\title{
INTEGRATION OF THE WATER AND SEWAGE SYSTEM MODEL WITH THE GIS APPLICATION
}

\author{
Tadeusz Żaba, Izabela Piech
}

\begin{abstract}
Summary
The GIS system has permanently entered the current operations of water supply companies. Due to the intensive development of cities and the resulting dynamic development of technical infrastructure, which is inherent in the functioning of the city, more and more extensive functionalities are expected from the GIS application. To fulfil the obligation to ensure continuity of water supply and sewage collection, it is necessary to constantly expand the system, extending it with new possibilities and integrate it with other software used in the company. We expect the created application not only to allow spatial identification of network sections, but also to simulate various operating conditions of the water supply and sewage collection system, and facilitate making current decisions related to the system operation and its regulation. Also, situations in which the system works in conditions that deviate from typical parameters are important. These situations can be caused by breakdowns, increased demand for water or heavy rainfall. To achieve the ability to support decisions independently of the GIS system, it is necessary to properly tare the hydraulic models of the system, and an extensive measurement system from which data is sent to the SCADA system via a data transmission system. The cooperation of the GIS and SCADA systems and hydraulic models allows for the creation of integrated software to support operational services. The paper presents a practical example of integration of the GIS system with hydraulic models of a water and sewage system, as well as available functionalities that allow improving the management of the water and sewage system in Krakow.
\end{abstract}

\section{Keywords}

GIS SCADA • hydraulic model • integration • water supply system • sewage system

\section{Introduction}

The GIS system has permanently entered the current operations of water supply companies. Due to the intensive development of cities and the resulting dynamic development of technical infrastructure, which is inherent in the functioning of the city, more and more extensive functionalities are expected from the GIS application. Today, information about the location and parameters of underground utilities is not enough. It is expected the software to become a tool for managing the current operations of a system and enabling the simulation of various working conditions. The capabilities of the GIS 
system make this system applicable in many areas including spatial planning, natural resource management, telecommunications, and energy.

Pursuant to the provisions of the Act on Collective Water Supply and Collective Sewage Disposal, a water supply and sewage company is required to ensure that its water supply and sewage facilities are capable of delivering water in the required quantity and pressure, as well as supplying water and sewage disposal in a continuous and reliable manner, and to ensure that the water and sewage discharged are of adequate quality. Such statutory provisions mean that water supply companies are increasingly using integrated computer systems whose purpose is to support technical services in their day-to-day operations.

Data on the water and sewage system in GIS and other programmes supporting activities related to the operation, maintenance and management of networks are used, among others, by dispatchers, the Water Supply Network Plant, Sewage Network Plant, Central Laboratory, Technical Department, and other services responsible not only for current functioning but also for the renewal and modernization of systems.

The paper presents a practical example of integration of the GIS system with hydraulic models of a water and sewage system, as well as available functionalities that allow improving the management of the water and sewage system in Krakow.

\section{GIS system and hydraulic modelling in the Krakow Waterworks}

Spatial Information System was implemented in the Municipal Water and Sewage Enterprise (MPWiK SA) in 2001. The data collected in the GIS system are organized in layers. Each layer contains data on one type of object. For layers, a set of attributes has been specified that are attached to the layer object along with information about its location in space. Currently, GIS covers the entire area of Krakow and supports not only operation but also the process of network development at all stages of implementation - from investment planning, through acceptance, to entering the fixed asset number.

The first hydraulic model for the water supply network was built as part of the State Committee for Scientific Research (KBN) project no. 5 T07E 04425 implemented by the Silesian University of Technology, Rzeszów University of Technology and Krakow MPWiK SA, Development of a model for the reliability of the water supply system (SZW) in the aspect of secondary water pollution in the water supply network. Another much more developed model was built by the Cracow University of Technology on proprietary ISYDYW 2.0 software (EPA-NET engine). The model was not connected to the GIS database.

In turn, in 2008, the Company's employees began construction of the first hydraulic model of the sewage system. Its construction was completed in 2014. Due to the fact that the main emphasis was on building a complete model, only a few catchments were properly calibrated. The model did not provide for exchange of information between the GIS database and the model base.

The experience gathered in the current operation of the models allowed to develop the view that it is necessary to expand and increase the functionality of the existing 
hydraulic models of the water supply and sewage network together with their integration with the GIS, SCADA, Billing systems, and to implement the system for modelling in real mode and predictive for the water supply network and sewage system.

\section{Integration assumptions}

When developing the assumptions for the integration of the hydraulic model of the Krakow sewage system, it was assumed that it would cover the entire combined sewage and sanitary system of Krakow and, in selected places, also inflows from the storm water drainage along with networks that are outside the company's operation. The model will also take into account inflows to the system from neighbouring municipalities that supply sewage to the Krakow sewage system. Currently there are six municipalities located in the vicinity of Krakow. The model will include objects such as sewage pumping stations, storm overflows, internal overflows, cascades, etc. The model will have the function of integrating the rainwater, sanitary and combined sewerage system with a digital terrain model including terrain obstacles such as buildings, curbs or walls. This will enable simulating the operation of the rainwater, combined sewage and sanitary sewage systems for given scenarios, also in the event of network overloads and floods on the surface. It will also allow for dynamic simulation and analysis of flooding and water flow in the area, their accumulation in non-drainage spots, and the return of waters to the sewage system from the area at run-off spots.

For the water supply network model, it was assumed that it would cover the entire water supply system of the city of Krakow together with transit lines DN 1000 and DN 1400 in diameter supplying water from the "Raba" Water Treatment Plant in Dobczyce. The model will include facilities such as water treatment plants, pumping stations, hydrophores, tanks, gate valves, zone gate valves, hydrants and all other water supply infrastructure facilities. The model will take into account current water consumption based on the billing base. Water sales to neighbouring municipalities will also be included. Currently MPWiK S.A. supplies water on a wholesale basis to 12 municipalities in the vicinity of Krakow.

The model will be directly connected to the SCADA system, from which it will obtain information about the current parameters of the network, which will allow generating network parameters in a continuous way for points where there are no measuring systems installed. In addition, the model will have the option of forecasting up to 168 hours in advance, and a retrospective forecast. It will also have a module for analysing water losses in the measuring sectors.

\section{The scope of integration of the GIS system and hydraulic models}

The Spatial Information System used in the company covers one hundred percent of the water supply and sewage network and is constantly updated. As part of the planned integration, the water and sewage network models will be expanded and their functionality will be increased in terms of combined systems and selected 
rainwater systems. In order to tare the models, a measurement campaign for the water and sewage network was prepared and carried out. After making the necessary measurements, detailed models will be calibrated using existing measuring devices installed in the network. Calibration of the built models will allow to optimize the operation of the water supply and sewage network based on selected scenarios from the analysis of floods, surface floods and network overloads taking into account the secondary inflow to the system.

At present, the company has a network of over 30 rain gauges in Krakow, the data from which will allow the construction of a system analysing forecasted precipitation using numerical forecasting models. Completing the data from the SCADA system and analysing them will allow calculating possible fillings, flows in channels, as well as potential floods in sensitive spots along with visualization of their range (calculated based on a two-dimensional triangular mesh model). The system will be designed to forecast flooding for designated catchments. It will be based on hydrological and hydraulic models, taking into account flows in the sewage system, precipitation forecast and hydrological measurements. In the case of lack of rain, it will visualize and show the current states (filling, flow) of collectors with the possibility of visualization on longitudinal profiles and map background.

The mathematical model of the water supply network will include diameters of water pipes from DN $50 \mathrm{~mm}$. It will take into account power sources, pump systems, tanks, gate valves, regulators and other controls in accordance with their operating mode. It will also import data on water demands from the billing system. The model is to reflect the unevenness of demands for seven consecutive days of the week starting from Monday; it is also to take into account the seasons. The water supply network model will also allow analysing the age of water in the water distribution system.

\section{Application of integrated decision support systems}

Dispatchers and network services make many decisions every day regarding the parameters and layout of the network. This is related to emerging failures, planned outages, network repairs and the investment process. The constructed and calibrated water supply network model will support making these decisions.

The model will have the ability to download measurement data from the SCADA system to build a system presenting the operation of the water supply network in real time, including the most important hydraulic parameters (pressure, flow, water velocity, water demand, cables ID, diameter, name of the object, direction of water flow at a given moment, gate valves, zone valves, gate valves status: red - closed; green - open) and the age of water in the network. Figure 1 presents a view of the screen combining data from the GIS and SCADA systems for the largest floodway system in the water supply network of the Piaski control room, from which water supplied from the Raba water treatment plant flows into the city.

The implemented integrated system will allow to build a Decision Support Platform, which will be an intranet tool supporting the management and maintenance of the 
water supply and sewage network. Depending on the permissions, all functionalities are to be available through a browser with the option of previewing and editing. The system will consist of 5 components:

1. Model of water supply network working in real time.

2. Intranet module for modelling the water supply network and sharing the results of model simulations from the detailed water supply model.

3. Intranet module for presenting the results of modelling the sewage network of the detailed model.

4. Real time forecasting model - system that informs about the network operations (flow, filling, velocity, etc.) and warns against flooding in the city in real time.

5. System to verify the confirmability of numerical weather forecasts.

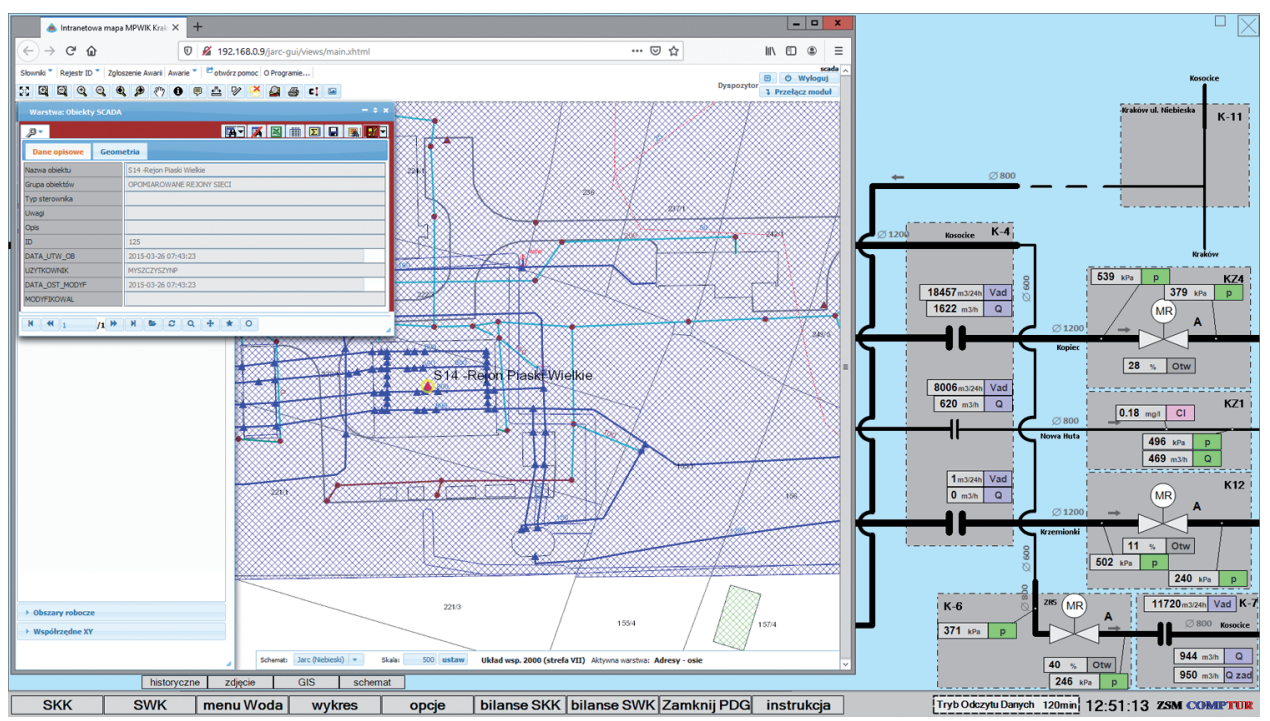

Fig. 1. Water supply system - Piaski Wielkie Control Room - integration of the GIS and SCADA systems

The system will also allow to estimate water losses in individual measuring zones based on 24-hour measuring sequences. Water losses will be calculated according to the IWA (International Water Association) methodology and presented in graphical and tabular form in the user interface. Figure 2 presents a view of the integration of the GIS and SCADA systems within one of the flow measurement points in the water supply network.

Calculated values of water losses, presented both for the entire network and for individual power sectors will include the following parameters:

- Water balance, including: 
- Water injected into the network.

- Authorized consumption, including sales and own needs.

- Water losses, including apparent and actual losses.

- Non-profitable water.

- Minimal night inflow.

- Unit indicator of real losses (Real Loss Basic or RLB).

- Unavoidable Annual Real Losses (UARL) coefficient.

- Infrastructure Leakage Index.

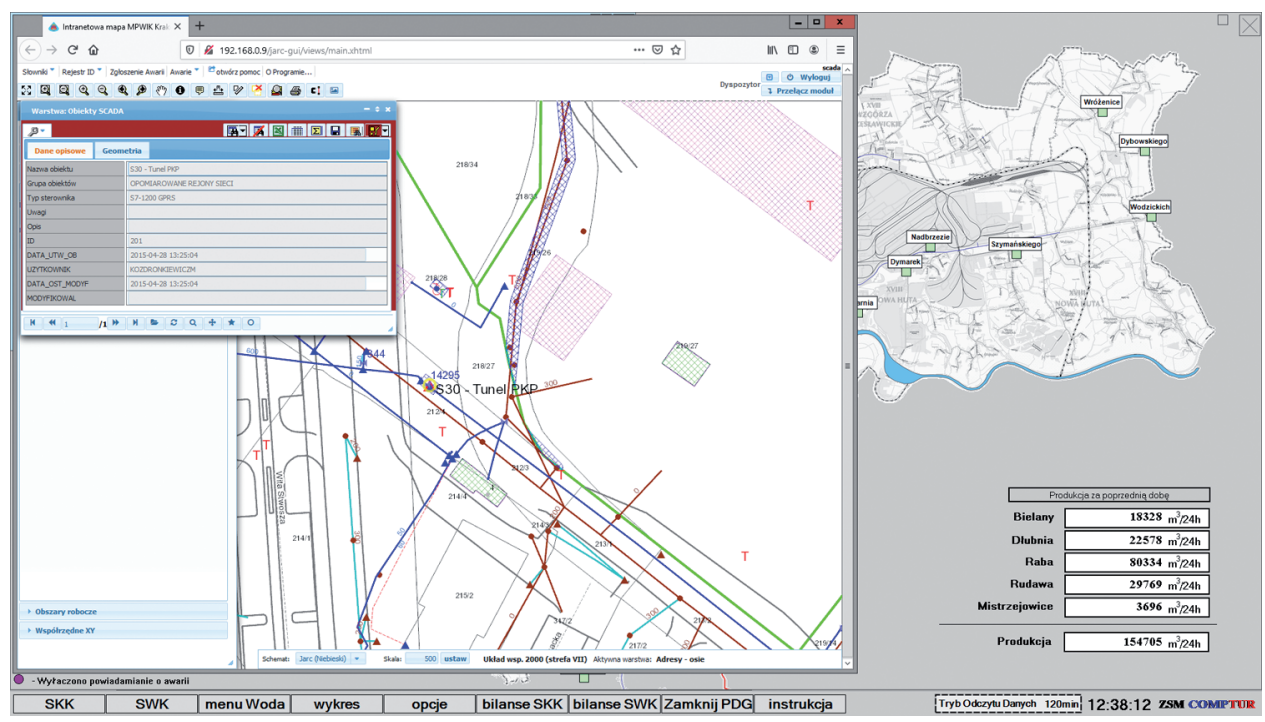

Fig. 2. Integration of the GIS and SCADA systems, and the hydraulic model - flow measuring point in the water supply network

The integrated system will allow the generation of charts for each floodway system and each object, showing the variability in time of parameters such as e.g. pressure, flow, water age, flow direction, flow velocity, etc. It will be possible to export data from each chart to an xlsx file. In addition, the system will enable simple hydraulic analyses and model calculations for such changes as e.g.:

- Pipe diameter change.

- Demand change.

- Pump system characteristics change.

- Pipe closing or opening.

- Valve closing, opening or change of its characteristics.;

- Water level change in tanks. 
The software will enable automatic indication on the map of valves necessary to close the section specified by the user, which is necessary e.g. in the event of a breakdown or planned renovation. In addition, it will be possible to analyse the operations of the water supply network within the scope of:

1. Analysis of pressure changes in the network presented dynamically for the assumed simulation time min. 24 hours ahead.

2. Analysis of water demands presented in a dynamic way for the assumed simulation time.

3. Analysis of changes in water flow in the network presented in a dynamic way for the assumed simulation time together with the presentation of the water flow direction.

4. Analysis of changes in water velocity in the network at a given time.

5. Analysis of pressure loss over a section at a given time.

6. Analysis of a number of backflows at a given time.

7. Analysis of a flow of water for firefighting, enabling determination of its pressure at a given flow or determination of a flow of water for firefighting at a given pressure.

8. Analysis of connection of new water supply network users.

9. Analysis of water age in the water supply network. The result layer must show the time during which water moves from the source to the users.

In terms of supporting decisions related to the operation of the sewage system, the model will allow to calculate the sewer network operation forecast with dynamic flooding visualization based on a long-term $1 \mathrm{~d}+2 \mathrm{~d}$ weather forecast (up to 48 hours). The drainage system operation forecast will be based on at least a 48 -hour precipitation forecast, updated at least once every 6 hours (calculation of the sewer predictive model at least 4 times a day based on input data from numerical weather forecast models and data from rain gauge).

Figure 3 shows the subsequent stages of integration of the GIS system with databases available in SCADA for the sewage network. The scheme applies to the Złocien pumping station - it is an important facility supplying sewage to the catchment of the Płaszów Purification Plant.

Due to the systematic densification of the Krakow agglomeration and the expansion of hardened surfaces, the sewage system has an increasing volume of rainwater. One of such points where we observe a systematic increase in the volume of sewage in the sewage system is the "Złocien" pumping station shown in Figure 3. The increase in sewage volume in the system results, among others, from the fact that a large part of the city operates in a combined system. Also, the more and more frequent occurrence of torrential rains should be added. Therefore, the possibility of simulating various events and variants of the sewage system operation will not only allow for efficient management of sewage and rainwater drainage, but also for the use of natural retention of the sewage system. 


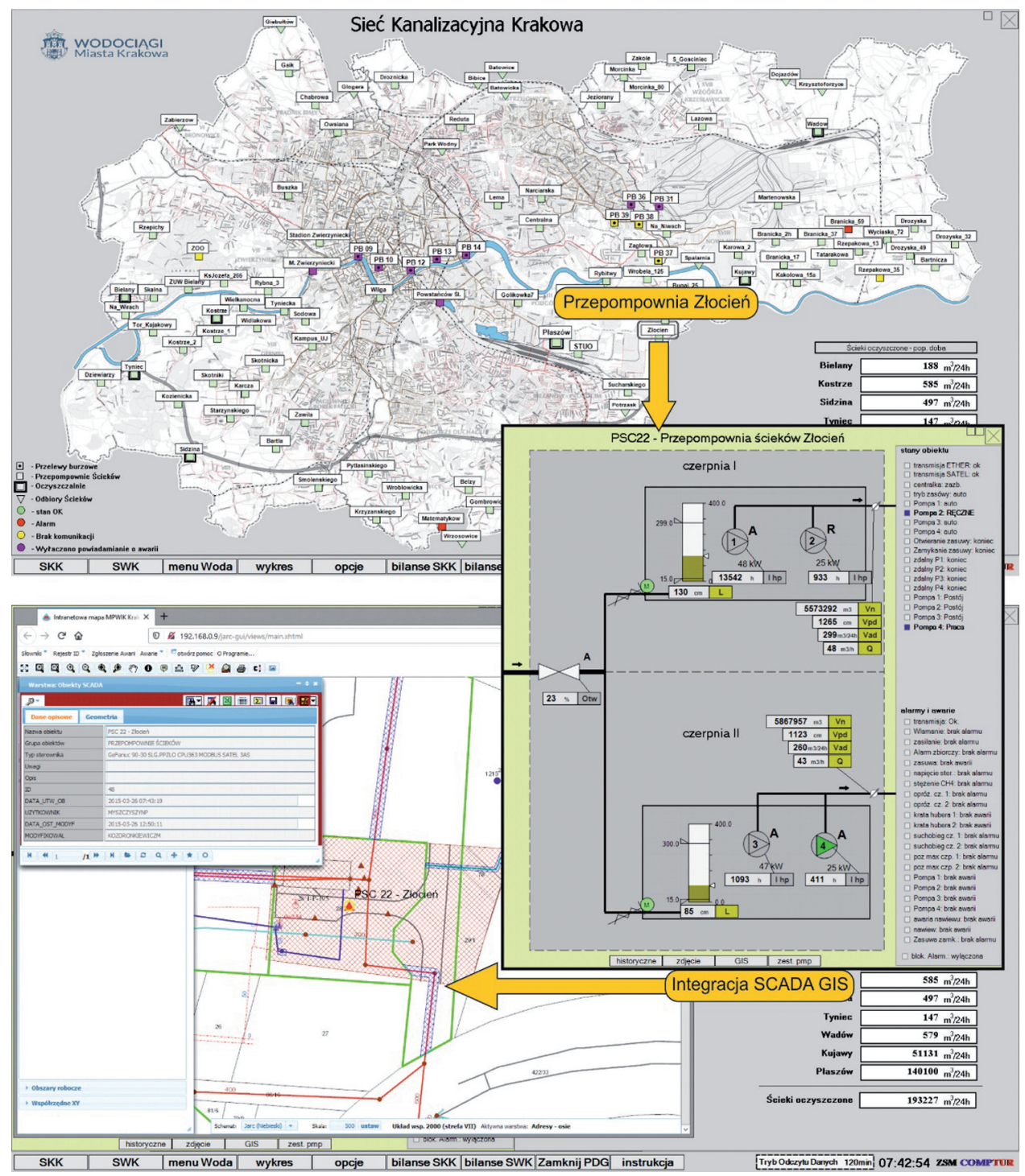

Fig. 3. Diagram of integration of the GIS and SCADA systems and the hydraulic model of the sewage network for the "Złocień" channel pumping station

\section{Conclusions}

To integrate the GIS system with hydraulic models working in the real-time system, it is not only necessary to have a properly correlated GIS system in which the data in the system will correspond to reality, but also a whole range of information on flows, pressures or gate valves is necessary. It is important to know the level of filling of sewer 
pipes. That is why it is a difficult undertaking and requires a number of preparatory works. The introduction of a decision support system is of particular importance in the event of a lack of water in a given area resulting e.g. from a major accident or sudden rainfall causing local flooding. The introduction of complete system integration will facilitate not only everyday operational activities, but also decision making in crisis situations. Rapidly made decisions in a crisis situation translate into limitation of effects and reduction of costs incurred by an enterprise. The system will also be an excellent tool for issuing technical information for newly planned facilities. The implementation will not only improve the efficiency and speed of operation, but will also positively affect the company's image and its assessment by service recipients.

\section{References}

Dąbrowski M. 2015. Wspomaganie zarządzania eksploatacją i utrzymaniem ruchu w sieciowych systemach technicznych. Management Systems in Production Engineering, 2(18).

Kwietniewski M. 2013. GIS w wodociągach i kanalizacji. Wydawnictwo Naukowe PWN, Warszawa.

Materiały Archiwalne MPWiK SA w Krakowie.

Myszczyszyn P., Glixelli M., Łukaszewicz M. 2017. MPWiK SA. Nowoczesne narzędzia zarządzania pracą sieci. Materiały konferencyjne, BMP, Łódź

Piasek Z. (ed.). 2015. Geodezja, kartografia i geologia inżynierska. Wydawnictwo Politechniki Krakowskiej, Kraków.

Dr inż. Tadeusz Żaba

Politechnika Krakowska

Katedra Wodociągów, Kanalizacji i Monitoringu Środowiska

ul. Warszawska 24, 31-155 Kraków

e-mail: tadeusz.zaba@interia.pl

ORCID: 0000-0002-0967-164X

Dr inż. Izabela Piech

Uniwersytet Rolniczy w Krakowie

Katedra Geodezji Rolnej, Katastru i Fotogrametrii

ul. Balicka 253a, 30-198 Kraków

e-mail:rmpiech@cyf-kr.edu.pl

ORCID: 0000-0002-6710-4387 